\title{
Non-descent vaginal hysterectomy for large uterus-safety and feasibility
}

\author{
Rameshkumar R., Sahana N. Naik*, Dhanalakshmi
}

Department of Obstetrics and Gynecology, Shree Dharmashatala Manjunateshwara College of Medical Sciences and Hospital, Sattur, Dharwad, Karnataka, India

Received: 02 August 2018

Accepted: 07 August 2018

*Correspondence:

Dr. Sahana N. Naik,

E-mail: sahanasurpur@gmal.com

Copyright: () the author(s), publisher and licensee Medip Academy. This is an open-access article distributed under the terms of the Creative Commons Attribution Non-Commercial License, which permits unrestricted non-commercial use, distribution, and reproduction in any medium, provided the original work is properly cited.

\section{ABSTRACT}

Background: Non Descent Vaginal Hysterectomy (NDVH) is removal of uterus through vagina in non-prolapsed uterus. The objective of the present study was to assess safety and feasibility of NDVH in patients with large uterus (>12 weeks size uterus).

Methods: Retrospective study was conducted in Department of Obstetrics and Gynecology of Shree Dharmasthala Manjunatheshwara (SDM) College of Medical Sciences and Hospital, Dharwad, India from May2014 to May 2017. Effort was made to perform hysterectomies vaginally in women with benign conditions with large uterine size. Information regarding age, parity, uterine size, blood loss, duration of operation, number of fibroids, other surgical difficulties encountered, intra-operative and post-operative complications were recorded.

Results: Total of 65 cases was selected for NDVH with large uterine size. All successfully underwent NDVH. 25 patients had uterus of 10-12 weeks size, 17 had uterine size of 12-14 weeks size. Mean duration of surgery was 90 min. Mean blood loss was $300 \mathrm{ml}$. Post-operative complications were minimal. All patients had early mobility with faster resumption to daily activities. Mean hospital stay was 4-5 days.

Conclusions: Non descent vaginal hysterectomy is safe, cost effective method of hysterectomy in women with large uterus requiring hysterectomy for benign conditions with less complications, shorter hospital stay and less morbidity.

Keywords: Fibroid uterus, Hysterectomy, Large uterus, Myomectomy, Non descent vaginal hysterectomy, Wedge resection

\section{INTRODUCTION}

Hysterectomy is the most frequently performed major gynecological surgical procedure. Non descent vaginal hysterectomy is considered safe for benign uterine conditions. Among women undergoing hysterectomy for benign disease, non-descent vaginal hysterectomy appears to be superior to laparoscopic hysterectomy and abdominal hysterectomy, as it is associated with faster return to normal activities. Although laparoscopic assisted vaginal hysterectomy and total laparoscopic hysterectomy are gaining popularity they are associated with the need for specialized instruments, specialized training for the same, increased operative time, increased cost and more complications. On the other hand, vaginal hysterectomy can be performed under regional anesthesia, with lower healthcare costs, with lesser complications and faster recovery. It is preferred in obese patients and in patients in whom the risks of general anesthesia are higher. It is also more cosmetic as there is no scar. When technically feasible, vaginal hysterectomy should be performed in preference to abdominal hysterectomy because of more rapid recovery and fewer febrile episodes postoperatively. ${ }^{1}$ Vaginal hysterectomy is not frequently performed in patients with large uterine size. $^{2}$ This could be because the vaginal route offers 
relatively limited space for surgical access to vascular pedicles and thus surgeons should have greater confidence in operating this vaginal route vs the abdominal route. ${ }^{3}$ The challenges to vaginal surgeon in cases of large uteri are, access to anterior and posterior pouches, securing the pedicles and decreasing the size of the uterus by various debulking techniques. These challenges are further enhanced by presence of adenomyosis, cervical or isthmic fibroid, psuedo broad ligament fibroid, adnexal pathology and previous cesarean section. Even in large uterus vaginal hysterectomy with debulking procedures is safe and feasible with less postoperative hospital stay and short catheter retention time. $^{4}$

\section{METHODS}

Between May 2014 and May 2017, 65 patients underwent nondescent vaginal hysterectomy.

All the patients were examined in outpatient and under anesthesia for the size of the uterus (Figure 1 and 2), location of fibroids, mobility of uterus, uterus free pelvic space, descent of the uterus, presence of cervicofundal sign in cases of previous cesarean section as described by Sheth S. ${ }^{5}$

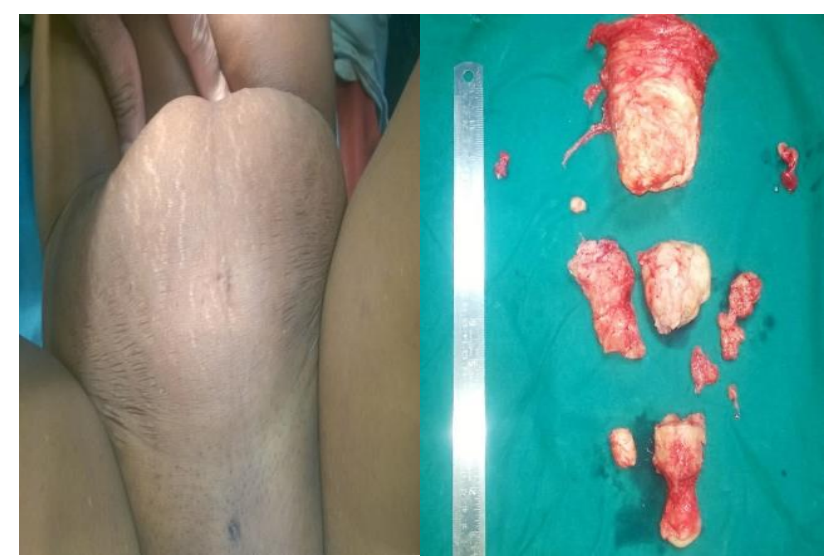

Figure 1: Uterus 16-18 week's size.

Informed consent was taken for vaginal hysterectomy and all the possible complications were explained including need for laparotomy in case of difficulty.

All patients were operated under spinal anesthesia in modified lithotomy position. Vaginal hysterectomy was begun by standard technique, diluted saline adrenaline or vasopressin infiltration was done, posterior pouch opened, anterior pouch was opened, and bladder dissected by standard method or using lateral window technique in cases of previous cesarean section. Bilaterally uterosacrals and mackenrodts ligaments were clamped cut and transfixed using no 1 polyglactin 910 suture.

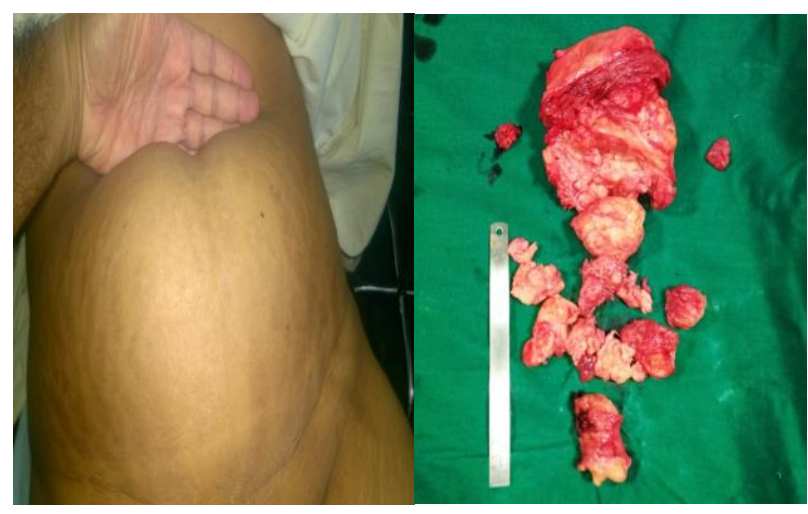

Figure 2: Uterus 20-22 week's size.

Uterine vessels clamped cut and ligated bilaterally using no 1 polyglactin 910 suture. After this step size of the uterus was reduced using various debulking techniques like coring (Figure 3), myomectomy (Figure 4), wedge resection, bisection or combination of these techniques.

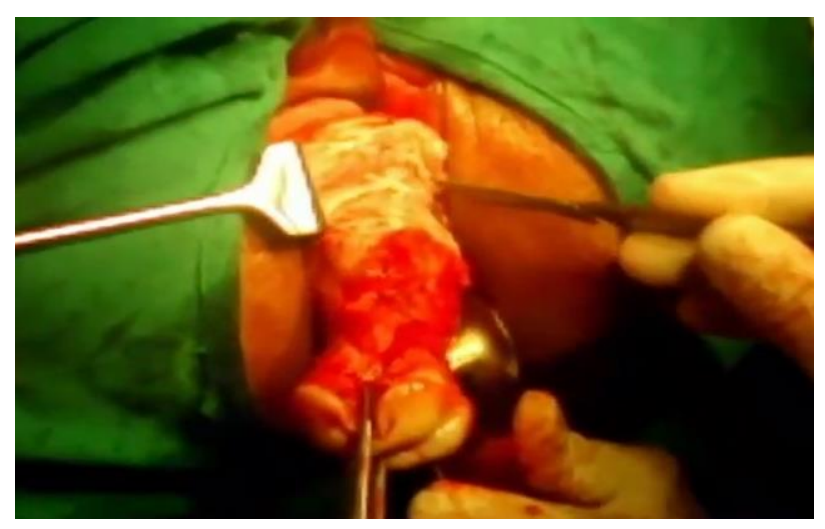

Figure 3: Coring.

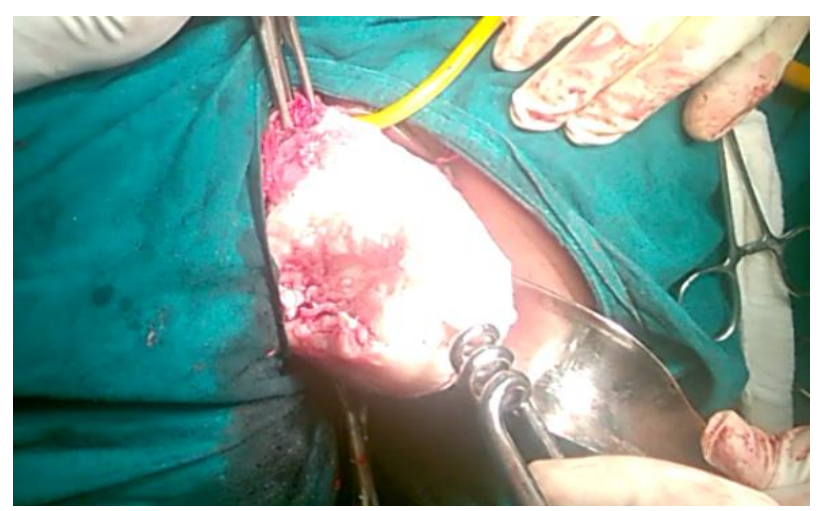

Figure 4: Myomectomy.

The basic principles to be followed during debulking techniques are to protect the bladder anteriorly and rectum posteriorly by using retractors, keep the orientation of the uterus correct, remain in the centre and avoid undue lateral extensions and to cut only as much as you can see. These principles are very important in avoiding injuries to bladder, bowel and ureter. After 
debulking the uterus cornual structures were clamped cut and transfixed using no 1 polyglactin 910 suture.

Bilateral salpingectomy was done in all cases and adnexectomy in any adnexal pathology like ovarian cyst (Figure 5) or in pseudobroad ligament fibroid (Figure 6) were removed.

Hemostasis was confirmed, mop, instrument and needle count done prior to vaginal vault closure, which was done using no 1 polyglactin 910 suture. The vault was suspended to uterosacral ligament. Urinary bladder was drained with foley's catheter.

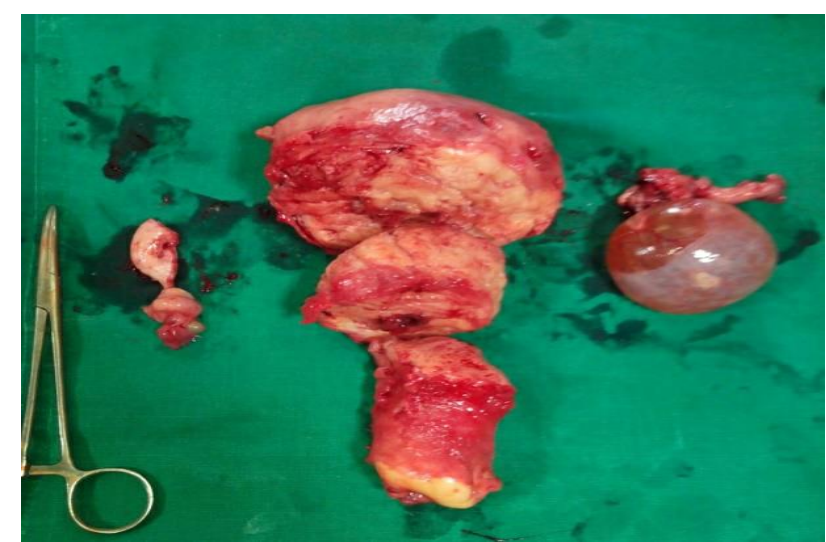

Figure 5: Adnexal pathology- ovarian cyst.

Deviation from standard technique was done in cases of isthmic (Figure 7) and cervical fibroids (Figure 8) where myoma was excised before clamping the uterine vessels. Bleeding in such cases was decreased by the infiltration of diluted vasopressin (20 units in 200cc normal saline) in the myoma.

Operative time was calculated from the time of incision on cervio-vaginal incision to vaginal packing. The amount of blood loss was calculated by the total of blood in the suction bottle and counting the mops and the need for blood transfusion in the post-operative period.

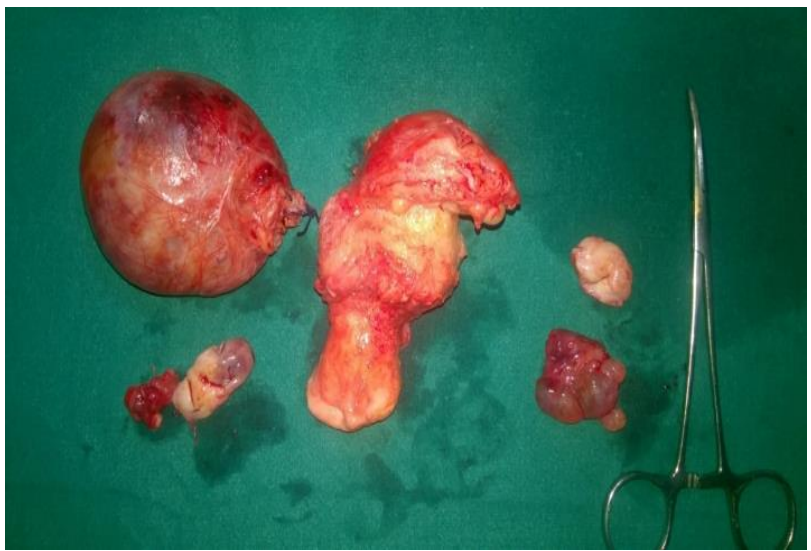

Figure 6: Pseudo broad ligament fibroid.

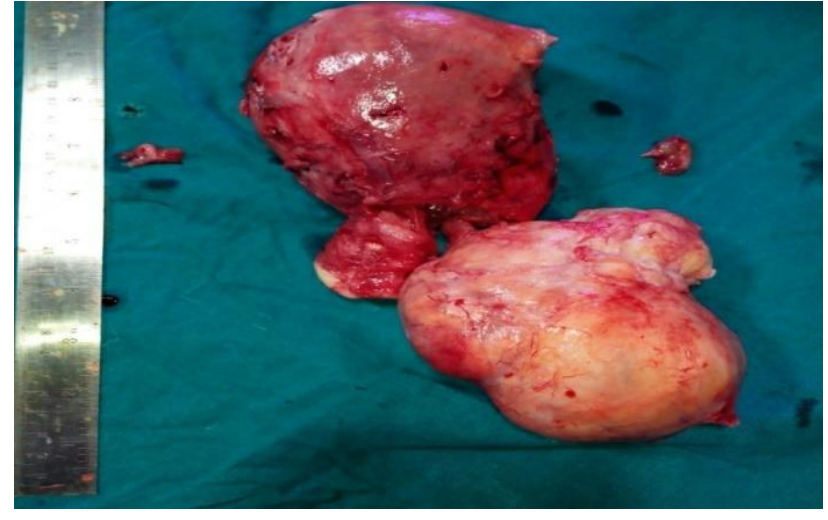

Figure 7: Isthmic fibroid.

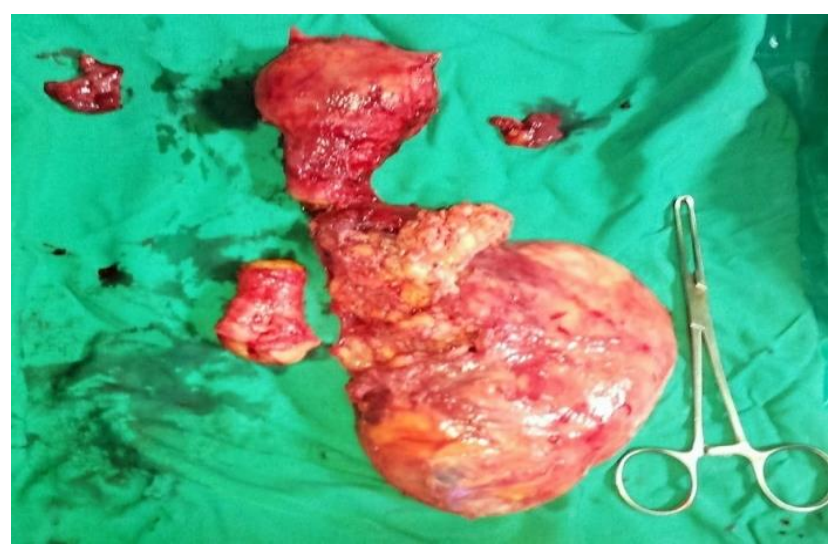

Figure 8: Cervical fibroid.

\section{RESULTS}

There were 65 patients in total who underwent NDVH for large uterus.

Table 1: Age distribution.

\begin{tabular}{|ll|}
\hline Age (years) & Number of cases \\
\hline $30-34$ & $3(4.62 \%)$ \\
\hline $35-39$ & $12(18.46 \%)$ \\
\hline $40-44$ & $19(29.23 \%)$ \\
\hline $45-49$ & $24(36.92 \%)$ \\
\hline$>50$ & $7(10.77 \%)$ \\
\hline
\end{tabular}

The most common age group undergoing surgery was 4549 years accounting to $36.9 \%$ of the cases (Table 1). Majority of them were para 2(57\%) and above, 12 cases (18.5\%) were nulliparous (Table 2).

Table 2: Parity wise distribution.

\begin{tabular}{|ll|}
\hline Parity & Number of cases \\
\hline Nulliparous & 12 \\
\hline 1 & 16 \\
\hline 2 & 23 \\
\hline 3 & 10 \\
\hline 4 & 4 \\
\hline
\end{tabular}


Table 3: Distribution of uterine size.

\begin{tabular}{|ll|}
\hline Uterine size (in weeks) & Number of cases \\
\hline $10-12$ & $25(38.46 \%)$ \\
\hline $12-14$ & $17(26.15 \%)$ \\
\hline $14-16$ & $8(12.31 \%)$ \\
\hline $16-18$ & $8(12.31 \%)$ \\
\hline $18-20$ & $5(7.70 \%)$ \\
\hline$>20$ & $2(3.08 \%)$ \\
\hline
\end{tabular}

In half of the cases the uterine size was up to 14 weeks, in 5 cases the size was 18-20 weeks of gravid uterus and in 2 cases the uterine size was more than 20 weeks.

Fifty percent of the cases had single fibroid and $10 \%$ of the cases had more than 4 no of fibroids (Table 3 and 4).

Table 4: Number of fibroids.

\begin{tabular}{|l|l|}
\hline Number of fibroids & Number of cases \\
\hline 1 & $32(49.23 \%)$ \\
\hline 2 & $12(18.46 \%)$ \\
\hline 3 & $10(15.38 \%)$ \\
\hline 4 & $4(6.15 \%)$ \\
\hline$>4$ & $7(10.77 \%)$ \\
\hline
\end{tabular}

Table 5: Duration of surgery.

\begin{tabular}{|ll|}
\hline Time (in minutes) & Number of cases \\
\hline$<45$ & $1(1.54 \%)$ \\
\hline $45-90$ & $33(50.77 \%)$ \\
\hline $90-135$ & $28(43.08 \%)$ \\
\hline$>135$ & $3(4.62 \%)$ \\
\hline
\end{tabular}

In fifty percent of the cases the surgery time was less than 90mins as in Table 5 and only in 3 cases it was greater than 135 mins.

The blood loss was less than $300 \mathrm{ml}$ in $80 \%$ of the cases and in only $3.08 \%$ of the cases the blood loss was more than $500 \mathrm{ml}$ (Table 6).

Combination of the debulking techniques was used in $90 \%$ of the cases with myomectomy being the most common single debulking technique used in $61.5 \%$ of the cases followed by coring in $36.9 \%$ of the cases as in Table 7.

Table 6: Blood loss.

\begin{tabular}{|l|l|}
\hline Blood loss $(\mathrm{ml})$ & Number of cases \\
\hline$<100$ & $10(15.38 \%)$ \\
\hline $100-200$ & $22(33.85 \%)$ \\
\hline $200-300$ & $20(30.77 \%)$ \\
\hline $300-400$ & $9(13.85 \%)$ \\
\hline $400-500$ & $2(3.08 \%)$ \\
\hline$>500$ & $2(3.08 \%)$ \\
\hline
\end{tabular}

Table 7: Debulking techniques utilized.

\begin{tabular}{|lll|}
\hline Debullking techniques & No. of cases & Percentage \\
\hline Bisection & 1 & 1.54 \\
\hline Coring & 24 & 36.92 \\
\hline Myomectomy & 40 & 61.54 \\
\hline $\begin{array}{l}\text { Wedge resection } \\
\begin{array}{l}\text { Combination of } \\
\text { techniques }\end{array}\end{array}$ & 8 & 12.31 \\
\hline
\end{tabular}

Table 8: Complications.

\begin{tabular}{|lll|}
\hline Complication & Number & Percentage \\
\hline Bladder injury & 0 & - \\
\hline Bowel injury & 0 & - \\
\hline Ureteric injury & 0 & - \\
\hline $\begin{array}{l}\text { Conversion to } \\
\text { abdominal route }\end{array}$ & - & - \\
\hline Blood transfusion & 2 & 3.08 \\
\hline $\begin{array}{l}\text { Post-operative } \\
\text { fever }\end{array}$ & 3 & 4.62 \\
\hline
\end{tabular}

Only 5 cases had post-operative complications (Table 8). Blood transfusion was required in 2 cases and 3 cases had post-operative fever. Surgical challenges were faced in two thirds of the cases $(64.6 \%)$ as shown in Table 9. There were 15 cases with previous lower segment cesarean section and 12 cases of nulliparity. Adenexal pathology was seen in 10 cases and 5 cases had cervical or isthmic fibroid.

Table 9: Associated surgical challenges.

\begin{tabular}{|lll|}
\hline $\begin{array}{l}\text { Associated surgical } \\
\text { challenge }\end{array}$ & $\begin{array}{l}\text { No. of } \\
\text { cases }\end{array}$ & Percentage \\
\hline Previous cesarean section & 15 & 23.08 \\
\hline Nulliparity & 12 & 18.46 \\
\hline Cervical /isthmic fibroid & 5 & 7.69 \\
\hline Adnexal pathology & 10 & 15.38 \\
\hline
\end{tabular}

\section{DISCUSSION}

The most frequently performed gynecological procedure is hysterectomy. Hysterectomy can be accomplished by various routes and the approach to it via the natural vaginal route has been the hallmark of gynecological surgeon and usually performed for uterine prolapse. ${ }^{6}$ The common limitations for vaginal hysterectomy being, nondescent of the uterus, previous pelvic scar, uterine size and adnexal pathology. In present study 65 patients underwent NDVH for large uterine size and all of them completed successfully with no conversion to abdominal route. Present study was done to demonstrate the feasibility and safety of NDVH for large uterus.

Majority of the patient were in the age group of 45-49 years, which was higher than the majority of the studies were the most common age group was 41-45years of age. Two thirds of the patients $(66.1 \%)$ of the patients were in 
the age group of 41-49 yrs of age which was similar to other studies. ${ }^{6,7}$ Parity of 2 or more than 2 was seen in only $57 \%$ of the cases which was similar to the other studies. Parity was single in $24.6 \%$ and $18.5 \%$ of the cases were nulliparous. Present study was similar to other studies with half of them being multiparous, but we did have significant number of nulliparous patients which was higher than the rest of the studies. ${ }^{8,9}$ In present study we had 50 cases with uterine size less than 16weeks of gravid uterus and 15 cases with a uterine size more than 16weeks, which was similar Bhadra et al. ${ }^{10}$ Fibroid uterus was the most common indication for surgery which was similar to other studies. ${ }^{6,8,10}$ More than fifty percent of the cases had 2 or more than 2 fibroids and the size varied from $2 \mathrm{cms}$ to $15 \mathrm{cms}$ in size. Average time duration for the surgery in our study was 90 mins which was similar to Gayathri et al but more than other studies. ${ }^{8-10}$ This increase in the duration of the surgery was due to the increase in the uterine size, the experience of the operating surgeon and the associated surgical challenges authors had in present study. There were 15 cases of previous cesarean section, 12 cases of nulliparity, 10 cases with adnexal pathology (ovarian cyst, broad ligament fibroid) and 5 cases of cervical/ isthmic fibroid. Blood loss was less than $300 \mathrm{ml}$ in $80 \%$ of the cases in our study which was slightly higher than the rest of the studies due to increase in the volume of the uterus. Only 2 cases needed post-operative blood transfusion. Debulking was required in $92 \%$ of the cases which was comparable to Bhadra et al and slightly higher than the other studies. $8,9,11$ Myomectomy was the single most common debulking technique used in 40 cases, followed by coring in 24 cases. Combination of the prior with /or wedge resection and bisection was used in $92.3 \%$ of the cases. There was no bowel, bladder or ureteric injuries in our study. Three patients developed post-operative fever and only two cases required blood transfusion.

\section{CONCLUSION}

Present study has demonstrated that non descent vaginal hysterectomy is safe and effective method of hysterectomy even in cases of large uterus. The factors that predict the successful outcome of non-descent vaginal hysterectomy for large uterus are the preoperative assessment of the size of uterus, the number and location of fibroid, uterus free pelvic space and use of debulking methods to reduce the size of uterus. Patience and perseverance are two essential factors in making non descent vaginal hysterectomy safe and effective method in cases of large uterus.
Funding: No funding sources

Conflict of interest: None declared

Ethical approval: The study was approved by the Institutional Ethics Committee

\section{REFERENCES}

1. Aarts JW, Nieboer TE, Johnson N, Tavender E, Garry $\mathrm{R}$, Mol BW, et al. Surgical approach to hysterectomy for benign gynaecological disease. Cochrane Database Syst Rev. 2015 Aug 12;(8):CD003677.

2. Unger JB. Vaginal hysterectomy for the woman with a moderately enlarged uterus weighing 200 to 700 grams. Am J Obstetr Gynecol. 1999 Jun 1;180(6):1337-44.

3. Dorsey JH, Steinberg EP, Holtz PM. Clinical indications for hysterectomy route: patient characteristics or physician preference?. Am J Obstetr Gynecol. 1995 Nov 1;173(5):1452-60.

4. DengwenHui, Zhang Yi, Lvqiu Bo, and other clinical observation method [J] Great remove the uterus transvaginal hysterectomy modified. Chinese Med J. 2013;93(41):3284-7.

5. Sheth SS, Goyal MV, Shah N. Uterocervical displacement following adhesions after caesarean section. J Gynecol Surg. 1997;13:143-7.

6. Alwani M, Srivastava I, Thakur R, Kaur R, Pathak S. Novel surgical approach: compare the efficacy of vaginal hysterectomy with abdominal hysterectomy in non-descent uterus. Int J Reprod Contracept Obstetr Gynecol. 2017 Mar 30;6(4):1342-6.

7. Gayathri KB. "Non Descent Vaginal Hysterectomy (NDVH) for Benign Gynecological disease: an institutional study on safety and feasibility from South India. IOSR J Dental Med Sci. 2017;16(11): 59-63.

8. Rupali D, Shivani A, Bharti MM, Soumendra KS. Non descent vaginal hysterectomy: an experience. J Obstet Gynaencol. 2004 Jul;54:376-8.

9. Shinde S, Aher G, Gavali U. Non descent vaginal hysterectromy (NDVH): our experience at a tertiary centre. Indian J Basic Applied Med Res. 2015;5(1):1516.

10. Bhadra B, Choudary AP, Tolassaria A, Nupur N. NonDescent Vaginal hysterectomy (NDVH): Personal experiences in 158 cases. AL Ameen J Med Sci. 2011;4(1):23-7.

11. Sushil K, Antony ZK. Vaginal hysterectomy for benign nonprolapsed uterus. Initial Experience. J Obstet Gynaecol Ind. 2004;54(1):60-3.

Cite this article as: Rameshkumar R, Naik SN, Dhanalakshmi. Non-descent vaginal hysterectomy for large uterus - safety and feasibility. Int J Reprod Contracept Obstet Gynecol 2018;7:3563-7. 